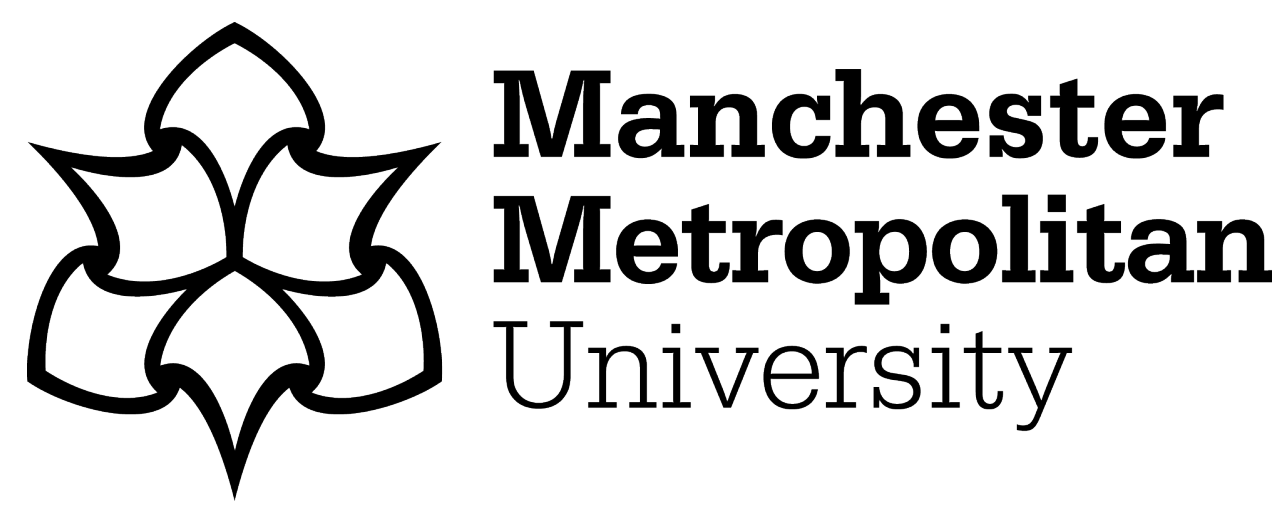

Colley, Helen, James, David, Tedder, Michael and Diment, Kim (2003) Learning as becoming in vocational education and training: class, gender and the role of vocational habitus. Journal of vocational education and training, 55 (4). pp. 471-498. ISSN 1363-6820

Downloaded from: https://e-space.mmu.ac.uk/14182/

Version: Accepted Version

Publisher: Routledge

DOI: https://doi.org/10.1080/13636820300200245

Please cite the published version 


\title{
Learning as becoming in vocational education and training: class, gender and the role of vocational habitus
}

\author{
Helen Colley, David James, Michael Tedder, \& Kim Diment \\ Published in 2003 in Journal of Vocational Education and Training Vol 55, No 4, pp \\ 471-496
}

\begin{abstract}
Official accounts of learning in vocational education and training emphasise the acquisition of technical skills and knowledge to foster behavioural competence in the workplace. However, such accounts fail to acknowledge the relationship between learning and identity. Drawing on detailed case studies of three vocational courses in childcare, healthcare and engineering - in English further education colleges, within the project Transforming Learning Cultures in Further Education, we argue that learning is a process of becoming. Learning cultures, and the vocational cultures in which they are steeped, transform those who enter them. We develop the concept of 'vocational habitus' to explain a central aspect of students' experience, as they have to orient to a particular set of dispositions - both idealised and realised. Predispositions related to gender, family background and specific locations within the working class are necessary but not sufficient for effective learning. Vocational habitus reinforces and develops these in line with demands of the workplace, although it may reproduce social inequalities at the same time. Vocational habitus involves developing not only a 'sense' of how to be, but also 'sensibility': requisite feelings and morals, and the capacity for emotional labour.
\end{abstract}




\section{Learning as becoming in vocational education and training: class, gender and the role of vocational habitus}

\section{Introduction}

Three decades ago, direct transition from compulsory schooling to work was the norm for many young people in England. Since the collapse of this youth labour market in the late 1970s, school-to-work transitions have become extended (Rikowski, 2001). Almost three-quarters of 16 year-olds now continue to participate in full-time education, and almost half of these pursue vocational education and training (VET) courses in further education (FE) colleges (DfES, 2001). This paper is focused on that provision (although we note here that the majority of FE students are adults). This expansion of the FE sector has produced a highly diversified market in VET, with courses that range from foundation to advanced level, and from general provision relating to broad occupational areas (such as Business Studies or Health and Social Care) to specialised training for particular jobs. This is in addition to youth training based in the workplace with (usually) one day per week off-the-job provision, some of which is also delivered in FE. Much VET was re-developed around the competence-based approach typified by National Vocational Qualifications (NVQs) in the early 1990s, and advocates for this model argued that, as a result, lecturers would have to meet the challenge of a new role: '[they] will need to be more than subject specialists and think more about the process of learning' (Jessup, 1991, p.106).

The challenge of understanding better the process of learning in FE is at the heart of our work in the national project Transforming Learning Cultures in Further Education (TLC), within the Economic and Social Research Council's (ESRC) Teaching and Learning Research Programme. Hodkinson and James (2004) provide a detailed overview of the TLC, but here we re-iterate some of its key premises: that teaching and learning are primarily social and cultural rather than individual and technical activities; they should therefore be studied in authentic settings; this in turn means addressing their complexity, through a cultural perspective on the interrelationships between individual dispositions and agency, and institutional and structural contexts. This hints at an important and deliberate ambiguity in the title of our project. On the one hand, we are investigating the potential to transform learning cultures in ways that enhance teaching and learning. On the other hand, we are also interested in the transforming effects of learning cultures: how do they impact upon the teachers and learners who enter them?

The TLC is studying 18 learning sites across four FE colleges in England. Over half of these sites provide VET for young people, and in this paper we draw upon our research in three such courses (Childcare, Health Studies and Electronic and Telecommunications Engineering). All are at the same Level 3 (Advanced) and of the same 2-year duration, and all combine a college course with work-based learning. The first two are full-time, whilst the latter is by day-release. We use the detailed case studies of these sites to explore the nature of vocational learning and the processes it entails, asking not only what it is that VET students learn, but also how they learn. In particular, we are interested in the relationship between learning and identity. How might we better understanding the processes of learning in FE if we see identity transformation - 'becoming' - as a central part of that process? We begin by reviewing the ways in which vocational learning has been conceptualised elsewhere. 


\section{Dominant concepts of learning in VET}

A range of 'official' accounts suggest how dominant approaches to VET construct learning. Prescribed curricula for VET courses emphasise the acquisition of skills (job-specific and transferable), along with 'underpinning' knowledge to ensure their appropriate deployment in the workplace. Moreover, the development of behavioural competence through this process of acquisition is central to the NVQ approach. Textbooks used on courses of teacher education in FE have for many years presented learning as an individualised, mainly cognitive process and have drawn upon a specific set of psychological theories of learning and motivation to inform teachers about it (see for example Armitage et al, 2003, also Curzon, 1990, Reece \& Walker, 1992, Castling, 1996). Their approaches are rooted in outcome-referenced models of curriculum design and delivery. The primacy of skills and knowledge acquisition they emphasises is supported by the current widespread use in FE of popularised theories of learning styles (e.g. Honey and Mumford, 1992) and the belief that their measurement will assist in the efficiency of an individualised approach.

The Further Education National Training Organisation (FENTO) is the national body that was tasked with writing the standards of occupational performance expected of FE teachers in England. These standards present a series of general statements about teaching and learning, which are held to be applicable across this vast and diverse sector. They do not distinguish between different subjects, but replicate the same approach towards both teachers and students as learners, referring throughout to the attainment of 'precise learning objectives and content' in relation to 'subject knowledge, technical knowledge and skills' (FENTO, 2003, p.14). They also construct learning as a predominantly individual process - even those relating to teaching via group activities still focus on individuals' acquisition of particular skills such as collaborative working. The domains of the social, cultural and emotional are represented only as a set of external factors which may affect learning (FENTO, 2003, p.18), not as facets of learning itself. The issue of identity is not considered at all.

There have, however, been some pervasive attempts to address identity in relation to vocational learning, and to answer the difficult question of how it is that people come to enter certain occupations. One of the most prevalent is Holland's theory of vocational personalities and work environments (e.g. Holland, 1959, 1997), which continues to be widely used in career guidance. Holland posits a tendency for congruence between six types of personality and six corresponding types of work environments, implying that successful vocational learning depends upon the preordained 'fit' between them, and is primarily as a technical process of acquiring the relevant sets of skills and knowledge. However, a key element that is missing from all these dominant accounts is any sense that vocational learning involves a process of becoming.

\section{Understanding learning as a process of becoming}

Other bodies of literature have explored this aspect of learning as identity transformation, beginning with early sociological studies of occupational socialisation. These explored adjustment after direct entry into the labour market, and tended to represent it as a relatively passive and 'once-and-for-all' absorption of the individual into the prevailing culture of a workplace and the norms of a particular role (Coffey and Atkinson, 1994; Killeen, 1996). More recent theories of work adjustment (e.g. Herriot and Pemberton, 1996) have drawn on economic theory to advance notions of the 'psychological contract' to explore processes of negotiation and behaviour between employees and employers. But these have not considered the 
relationship between vocational learning and identity, and again, they are relevant to workplace situations rather than FE.

The theoretical approach of the TLC project means that we are interested in the way that cultural approaches have been used to understand learning in the context of VET. For example, Bates (1984) discussed the role of vocational curricula and careers education in school as a form of 'anticipatory socialisation' prior to labour market entry, that seeks (with varying degrees of emancipatory or controlling intent) to promote young people's adjustment to the general demands of employers for a disciplined workforce, or to the limited range of opportunities on offer to them. Willis (1977) provides perhaps the best-known case study of how working-class boys at school actively - but counterproductively - co-constructed classed and gendered processes of socialisation leading them into low-skilled, low-paid jobs. Although these present a more active concept of socialisation, they do so in relation to compulsory schooling rather than FE, and in relation to general processes rather than specific instances of vocational learning.

Lave and Wenger's (1991) work has been influential in advancing the concept of learning not as acquisition but as participation. They offer a complex understanding of how learning for specific occupations occurs in the workplace itself, and conceptualise the process as one of legitimate peripheral participation in communities of practice. They argue that it is social participation, rather than cognitive acquisition, which enables newcomers to learn from more experienced practitioners, and it is intimately bound up with the social context in which it is situated. Here, immersion in the social, cultural and emotional aspects of work are not merely factors which influence learning, but are central to it. Becoming is a crucial part of this process:

[S]ocial communities are in part systems of relations among persons. The person is defined by as well as defines these relations. Learning thus implies becoming a different person with respect to the possibilities enabled by these systems of relations. To ignore this aspect of learning is to overlook the fact that learning involves the construction of identities... identity, knowing and social membership entail one another... (Lave and Wenger, 1991, p.53)

At the same time, particular forms of learning (or occupations) may attract people from similar backgrounds or with similar dispositions:

[C]ommunities of practice consist of and depend on a membership, including its characteristic biographies/trajectories, relationships and practices. (Lave and Wenger, 1991, p.55)

Such a view challenges the essentialist idea that certain people are inherently suitable for certain jobs. A cultural or situated perspective on learning allows us to ask more complex questions about how learners are prepared to enter occupations (or, in some cases, are diverted away from them). What is it that makes learners feel they are suited to particular jobs? What are their experiences of the community of practice they seek to enter? How does their sense of identity change as they become a member of that community? Such questions are directly relevant to the experience of learning in the VET sites we are researching. However, Lave and Wenger's exclusive emphasis on the authenticity of workplace learning means that they tend to dismiss 
the value of learning in more formal educational settings such as FE (Colley et al, 2003).

Frykholm and Nitzler (1993) also consider learning as an active process of becoming, but in the context of formalised courses. Their study of vocational and career education in a Swedish secondary school, drawing on the theories of Bourdieu and Bernstein, treats the issue of identity as central. Their analysis directly challenges the assumptions of VET curricula and the FENTO standards, as they suggest that:

...vocational teaching is characterized more by socialization than by qualification, i.e.... it is more a question of transmitting dispositions and attitudes than of giving the knowledge and skills required for specific tasks. (Frykholm and Nitzler, 1993, p.434)

Key to this view is their concept of vocational 'notion'. Notions are more abstract than attitudes and values, and may be general or may relate to specific sectors of employment. They comprise both subjective and structured aspects of the ways in which people 'organize and bring meaning to their surrounding world', including work and occupations (p.436). In the classroom, vocational learning is actively coconstructed by teachers and students, determined in part by the dominant structures of thought that prevail in particular employment sectors and particular occupational levels within those sectors. Teachers adapt their pedagogy to the habitus (rather than general ability level) of their students, but at the same time students' habitus is informed by vocational notions which also influence teachers' discourse. Notions can therefore exert a powerful influence upon identity, even in the classroom:

Students with different habitus and notions are, through linguistic market forces, subjected to sanctions and structural influence towards mental homogenization. This structural influence also applies to the teacher who, to a certain extent, is 'forced' to adjust his or her teaching to the dominating structures of thought. (Frykholm and Nitzler, 1993, p.442)

This is an analysis which we have found helpful in understanding the learning processes taking place in the VET courses that we are studying. There is much in their specific case studies of vocational courses in metalwork and healthcare that resonates with the FE learning sites we shall describe in this paper. For example, they argue that the key learning outcome of metalwork lessons was 'adjustment, conformity and submission to superiors' (p.437), while in healthcare, it comprised idealised devotion to caring for others, conformity to hierarchical work relationships, and a willingness to abnegate one's own interests 'especially regarding wages' (p.440). These findings make visible the hidden curriculum which official versions of learning in VET, with their 'precise learning objectives' of 'technical knowledge and skills' (FENTO, 2003), serve in part to obscure.

However, there are some limitations to Frykholm and Nitzler's study. It investigates school settings, rather than the FE sector with which we are concerned, and focuses on courses which are exclusively classroom-based, rather than the combination of college course and workplace experience that our sites provide. The data are drawn from only five case studies, three of which were of more academic courses, and no follow-up studies were conducted. Moreover, this was but a substudy of learning processes within a small-scale evaluation of other aspects of vocational and career education. It therefore suggests the need for richer case study 
data, for studies in FE contexts, and for the theoretical development of their ideas that such data would allow.

In the context of post-compulsory VET, Bates (1991, 1994a) has also challenged the view that learning consists primarily of skills and knowledge acquisition, and that occupational 'fit' is a question of matching personality traits to job factors. She argues that a sense of 'suitability' for a certain type of work is constructed socially and culturally, and that VET - from recruitment through to qualification and labour market entry - plays a powerful role in that process, mediating between classed-gendered backgrounds and the demands of the workplace. Her study of a youth training scheme for girls going into care of the elderly showed how the scheme effectively selected and then further sifted and acculturated the trainees. All the trainees had been 'cooled out' of ambitions to work in slightly higher status occupations such as childcare. Some of the girls proved unable to develop the requisite caring dispositions for this work, and became isolated then excluded. The disappointed but successful 'care girls' eventually came to regard their work as a 'job which is right for me' (Bates, 1994a), as they also became 'the right person for the job'. This re-construction of their tightly restricted occupational choice and of their own identities is redolent of what Bourdieu (1986) terms 'the choice of the necessary'.

Similar analyses have been used in other individual case studies of a fashion design course (Bates, 1994b), a catering course (Riseborough, 1994a) and a bricklaying course (Riseborough, 1994b) within the same research programme as the 'care girls' study (the ESRC's 16-19 Initiative). Hodkinson et al (1996) also utilised the concept of vocational 'notion', analysing the interplay of habitus and field in their study of 10 young people moving from school into VET, but they were primarily concerned with the process of career-decision making rather than that of learning itself. This paper therefore represents a contribution to understanding the process of learning in VET, by offering a comparison of three different vocational courses in FE, based on in-depth insights into teaching and learning in each site. We also seek to refine further the theoretical concepts of identity transformation in relation both to learning cultures and to the vocational cultures with which they are associated.

Our interest in 'how the person is defined by as well as defines relations' within a community of practice (Lave and Wenger, 1991, p.53) leads us to call upon key concepts from the social theory of Pierre Bourdieu. Habitus is a concept which expresses complexities that are not perhaps so well conveyed by the notion of 'identity'. It incorporates both the subjective, personal dispositions and the collective, structural pre-dispositions shaped by class, race and gender that are combined in each individual. In the context of our research, field is a concept for expressing the sets of social relations characteristic of particular learning sites, educational institutions, occupational workplaces, and their associated practices. We can see the relevance of these concepts to a view of learning as developing membership and identity, in Bourdieu's argument that:

...the relation between habitus and field operates in two ways. On the one side, it is a relation of conditioning: the field structures the habitus, which is the product of the embodiment of immanent necessity of a field... On the other side, it is a relation of knowledge or cognitive construction: habitus contributes to constituting the field as a meaningful world, a world endowed with sense and value, in which it is worth investing one's practice. (Bourdieu quoted in Wacquant, 1989, p.44) 
We would wish to highlight two of the ways in which a Bourdieusian approach assists in the study of the learning process in VET. First, whilst it is easy to distinguish between roles (to do with functions, norms and the like) and identity (to do with individuals and meanings), it is more difficult to conceptualise the two without suggesting that one must always cause the other, in either direction. What is required here is a language, or at least some concepts, that already allude to a process of mutual definition between structure and agency. The concepts of habitus and field, which always imply each other, are arguably some of the most useful theoretical 'tools' for keeping social practice (which is always both structure and agency) in view.

Second, the approach helps guard against too literal or compressed a concept of socialisation, suggesting that we should not confine our interest to instances of short-term cause and possible effect in pedagogical action (though we should never rule these out completely). In addition to examining the transmission and shaping of particular attitudinal and behavioural attributes, the approach suggests we should also look at ways in which VET may function to institute or to realise various 'becomings' that are immanent, socially inscribed - in a sense, 'waiting to happen'. They are instances of what Bourdieu (1982) calls 'the subjective expectation of objective probability'.

Put together, these two arguments encourage an understanding of any particular learning process in the context of lifelong habitus formation. For example, Bourdieu discusses the embodiment of gendered dispositions in similar terms:

The formative process, Bildung, in the full sense, which brings about this social construction of the body only very partially takes the form of explicit and express pedagogic action. It is to a large extent the automatic, agentless effect of a physical and social order entirely organized in accordance with the androcentric principle (which explains the extreme strength of its hold).

(Bourdieu, 2001, p.24)

In this paper, we use such a cultural approach to explore themes of becoming in VET. How does it help us to understand vocational learning cultures in VET sites across the TLC project, and potentially across FE as a whole? Can the concepts of field and habitus, of communities of practice and vocational becoming, provide us with a richer understanding of how VET operates through its social and cultural practices? And can such understanding lead to opportunities for enhanced practice for transforming learning cultures - on the part of those involved as teachers, managers or policy-makers?

\section{Methods}

As noted in our introduction, we explore these questions by drawing on the data from three VET learning sites in different colleges across the TLC project. (The project represents a collaborative partnership between four universities and four FE colleges in England.) All are two-year courses at Level 3 (Advanced), in childcare, healthcare, and electronic and telecommunications engineering respectively. Like many courses in FE, they are highly gender-stereotyped. They are also populated mainly by students from working-class backgrounds, whose families often have no experience of higher education. Our decision to concentrate our analysis on such sites and their students is made purposively, in the hope of rendering more visible both 
aspects of habitus as a 'structuring... and structured structure' (Bourdieu, 1986, p.170). All the sites have a substantial amount of work-based learning included throughout, although the relationship between the college course and the work-based element is significantly different in each case.

The data used here were generated with the first cohort we tracked through each site for two years from September 2001. The methods adopted throughout the TLC project (see Hodkinson and James (2004) for further detail) are designed to facilitate its exploration of the social and cultural aspects of learning. They focus on particular 'learning sites' in depth, so that the study of each site is both longitudinal, following each cohort through their two years on the course, and multi-dimensional: data are generated through repeated semi-structured interviews with six students in each site; through repeated semi-structured interviews with the site tutor; through a questionnaire administered to all students in each site; through observations of the sites; and through reflective research journals kept by the tutors. The relationship between the large research team (16 researchers, four of whom are seconded from the participating colleges) and the site tutors is a collaborative one, so that analysis of the data has been developed through both FE-based 'insider' and university-based 'outsider' interpretations, as well as through discussions of emerging cross-project themes in the core research team's national meetings. These methods have allowed the construction of highly detailed case studies of every TLC learning site, which have been shared across the team. Although we only have space in this paper to describe three sites, our thinking has been shaped in the light of data and analysis across the project. We begin by offering brief accounts of each of our selected sites, centred on students' experiences of learning as becoming.

\section{Becoming a nursery nurse}

The students in our first site are studying for the CACHE Diploma in Childcare and Education. (CACHE is the acronym for the Council for Awards in Childcare and Education, and its Diploma is the most common qualification required for working as a nursery nurse, which is a registered occupation in the UK. A detailed case study of this site can be found in Colley, 2002a, see also Colley, 2003a,b.) Although the CACHE Diploma can allow progression (after further study in higher education) into careers such as teaching and nursing, in practice the large majority of students go into employment as nursery nurses in the private sector. The students are all from working-class backgrounds, and are almost all 16 and 17 yearold girls, except for one mature woman and one young man. The course is located in the overwhelmingly female health and social care department. The students' time on the course is divided equally between taught sessions in college and regular work experience placements. They must pass formal assessments of their work in placement, as well as coursework and a terminal examination, in order to achieve the qualification. In addition, many of the students have prior experience and part-time jobs in childcare, and an ability to do well in placement is regarded by the tutors as being more crucial than strong academic performance.

Many of the students have arrived on the course as a result of having their ambitions to become teachers or nurses lowered due to poor results in school examinations. Childcare is low-status work within the field of education, and nursery nurses are usually subordinate to professionally qualified teachers or healthworkers. It is also a heavily gender-stereotyped occupation: $99 \%$ of nursery nurses are female. Furthermore, they are poorly paid, earning little more on average than supermarket 
shelf-stackers, and sometimes receiving only the statutory minimum wage (Low Pay Unit, 2002).

As the students have progressed through their first year of training, their accounts of their learning in the workplace have focused around three key issues: recognising the developmental role of the nursery nurse; keeping their own feelings under control in the face of crisis and provocation; and developing a suitable personal disposition for childcare work. Early in the course, students often said they enjoyed playing alongside small children in nursery classes, but by the end of their first year, most saw their role quite differently, as in this typical comment:

CACHE student 1: That's what I've kind of learned, now... I teach, although I was playing with them [the children]... If you went and just played with the kids and just not said 'owt, like 'How many bricks are there?', they wouldn't really ever learn, would they? So you've just got to really think about it. Make `em count the bricks, and say how many bricks there are, and also play at the same time.

Comments like this allude to moving away from identification as a child among other children, and towards the adoption of roles deemed more mature. They also imply a paradox: students had to engage more intensely with children, but remain purposefully detached at the same time. Students expressed this paradox even more intensely in relation to aspects of the work they found distinctly unpleasant.

Alongside enjoyable stories from their placements were many less happy tales of toileting, tantrums, and physical aggression or cheekiness from the children. Again, the following is one of several examples:

CACHE student 2: Children can wind you up! You'd say something to them, and then they're really, really cheeky. They've learned how to answer you back, so they're gonna do it. And they can wind you up, and suppose you've got a short temper? But saying that, I've got a short temper, but I don't let them try it.

Students had to limit their affection for their charges, learn not to be too 'loveydovey' or 'get attached', and be stern when necessary. They also had to learn not to react when provoked, and to keep their own emotions under control while also trying to manage the extreme emotions young children can display.

The tutor actively works to develop these emotional capacities. In a group tutorial session after the students' first few days in placement, she encouraged them to talk about their 'best and worst' experiences. While most had found it mainly enjoyable, moments of stress and repugnance also surfaced: embarrassment at taking little boys to the toilet; finding oneself soiled with children's 'puke' and 'wee'; and being hit by children. The tutor emphasised the correct behaviour students should display in these situations:

CACHE tutor: Don't forget, you've got to stay cool and say, [nonchalant tone] "Oh, that's not a very nice thing to do, is it?" and keep your own feelings under control.

This emotional labour (Hochschild, 1983) proved difficult and exhausting at first. However, when we fed this evidence from the research back to the group at the start 
of their second year, they responded animatedly that 'You're a different person when you're at nursery than when you're at home!' They agreed that this enabled them to stay calm as a nursery nurse in situations where they would 'lose their cool' with younger siblings or friends at college.

Students were also expected to develop certain dispositions and demeanour in order to appear 'professional'. Nursery nurses, in caring for other people's children, have to appear to be 'nice girls', and convey a sense of moral propriety. This ranges from a strong emphasis on the need for demure dress in placement, which most of the group gradually adopted in college as well, to tutors' deliberate efforts to get the group to 'gel' and bond emotionally with each other. Some of the more compliant students quickly came to regard themselves and their friendship group as 'nice', and to characterise others as 'rough'. They lived in leafier suburbs of the city, usually with both parents. Their parents did not work in lower-paid manual jobs, but as police officers, secretaries, and other more 'white-collar' occupations. 'Rough' students lived in the more deprived areas of the city, in poorer and less stable family situations, and were criticised for using obscene language, bullying others, and dressing in exotic fashions. As the year wore on, a number of these students became isolated and then eventually excluded from the learning site in various ways. They were deemed, by tutors and by classmates, to be unsuitable for working with small children. 'Nice' students, from upper strata of the working class, were far more likely to succeed in lasting the course and becoming 'the right sort of person for the job'. At the end of the course, those interviewed explained that the patience and self-control they had learned in the nursery was now part of their persona at college and at home. They felt they had become nursery nurses.

\section{Becoming a healthworker}

Another learning site at a different college comprises an all-female group of 16 and 17 year-olds studying for the BTEC National Diploma in Health Studies. (This is a general vocational course preparing students for entry into a range of healthcare occupations. A detailed case study of the site can be found in Tedder, 2002.) The students come from a number of villages across the catchment area of the college and parental occupations suggest mainly working class backgrounds. Most live with both parents. Many of the students achieved high grades in their final GCSE examinations at school, and some thought they were out of step with their school peers in opting for a vocational BTEC course rather than the academic GCE A level route.

As in the CACHE Diploma, a substantial part of the students' time is spent in work placements. Many of these students have prior work experience and part-time jobs in the care sector, but personal experience of elderly relatives or of siblings with learning difficulties also plays an important role in their initial orientation and subsequent development towards a caring role. Most aspire initially to careers in nursing or midwifery, although tutors try to broaden such ideas to include other healthcare occupations such as radiography and occupational therapy. Like nursery nursing, these are strongly gender-stereotyped occupations, but all of them require further study in higher education. Here too, the students display conventional and modest physical appearance and modes of dress. Another similarity with the CACHE course is the sense of strongly-bounded and gendered physical location within the college. One student described the engineering department - populated predominantly by male mechanics and welding students - as 'the scary places' in the college, and as 'non-girl territory'. 
Tutors expect much of the work placements as opportunities for the students to develop skills in practical caring and appropriate behaviour, and placements are assessed through a Vocational Practice module. As with the childcare students, familiarisation with caring work roles and development of skills have gone hand in hand with learning to keep control of feelings and the development of appropriate dispositions within the workplace and at college. The healthcare students undertake placements in three sectors: childcare, care of the elderly, and care of people with learning difficulties. In childcare placements, these students also had to learn not to shout or react immediately to children's misbehaviour. In working with the elderly, students had to cope with challenging aspects of bodily care: bathing, feeding, treating infected wounds, and toileting. Again, this required a certain detachment:

Healthcare student 1: (Laughs) I have felt slightly ill sometimes... But when you can deal with things like extremely bad pressure sores and things like that and it doesn't bother you ...- it smells horrendous, absolutely horrendous. A lot of people say "Well, how can you do that?" but you don't really think of it that way, you just get on and do it.

Elderly people could at times be agitated, aggressive and violent, and need calming, all of which made emotional demands on the students. Working with the learning disabled caused anxieties and stress for some, though others learned to empathise with their clients' feelings.

Maintaining a cheerful outward appearance was an important disposition students were expected to develop. A student who worked part-time as a care assistant with the elderly, summed up how essential she felt this was to her work:

Healthcare student 2: The main thing is always have a smiley face, that's the main thing, it's true. It works wonders. Everyone gets a bit down, but if you're walking round looking miserable, it doesn't make the residents feel any better. But if you're walking around, you're happy, you're chirpy, you like talking, then it helps.

The tutor confirmed that students are assessed by their supervisors and by their Vocational Practice tutor on their ability to communicate with clients and to respond to their needs. Their commitment to and integration in the learning site are judged in part through criteria like punctuality but also, more informally, according to the degree of cheerfulness they display:

Health Studies tutor: I can't say there is one [student in the group] who is nasty, whether it's the nature of people who want to go into caring, but I was really impressed with one girl. When you seen her working with people with special needs, she is lovely, has an open attitude. And another girl, she doesn't like it, but she has a lovely open smile, even if she can't understand the conversations, she's there and talking away with them, it's so impressive.

However, substantial emotional demands are made on students in their relationships with clients and in maintaining their emotional integrity. Even those who may appear well-integrated are at risk of finding that such emotional labour may exact a high cost in terms of stress and burn-out (Hochschild, 1983). 
There are some important differences between the Health Studies course and the CACHE Diploma. Health Studies has a strong science focus which gives it academic kudos above other care courses. However, the traditions of 'objectivity' in the natural sciences do sometimes provide a rationale for the marginalisation of affective and ethical matters raised by student experiences. Academic knowledge in the course has been privileged above practical experience in the assessment regime. Nevertheless, there are indications of change: in recent years BTEC classified the Vocational Practice module as an essential module and have included it as a central element of the recently introduced Integrated Vocational Assignment, student work that will be externally marked.

Although most of the students aspired to a nursing career, their envisaged vocational destinations became more tentative and more provisional over time (see Davies and Tedder, 2004). In some cases it appears that the work placements, rather than opening new possibilities for the students, served to confirm which areas of care the students would choose not to work in. Some students appeared to have limited their aspirations by the end of the course, deciding not to pursue the higher education necessary to become a nurse (or radiographer etc.). One aspect that these two sites appear to share, however, is a common view about the nature of care. The students' capacity to walk the emotional tightrope of appropriately combined involvement and detachment in caring for others is an important boundary of inclusion and exclusion in both these learning cultures.

\section{Becoming an engineer}

In a site at a third college, students attend on a day-release basis, often through Modern Apprenticeship schemes, to study for a BTEC National Certificate in Electronics and Telecommunications Engineering. (A detailed case study of this site can be found in James and Diment, 2002.) The course may be described as syllabusled with a highly technical content, and most students are already working in these industries. The ostensible focus of the course is therefore on technical skills and knowledge, quite different from the other sites' focus on personal services, caring for others and capacities for emotional labour.

Engineering is a male-dominated area of work, and the electronics and telecommunications sectors are no exception. Apart from one woman, all of the students in this site are men, as are all of the tutors. Of the two female students who started the course, one soon dropped out, and the other experienced periods of illness and other circumstances that made continuation difficult. We have already seen how the healthcare students perceived the masculine domain of the engineering department in their own college as alien and somewhat threatening. Our own fieldwork observations refer to the 'maleness' of the physical space this site occupies within its college. Apart from the administrative staff, women are rarely seen there; motorcycles are ranged outside; and at various times of the day, groups of young men flank the entrances smoking or using mobile 'phones. Other data from this site confirm Maull's (1998) suggestion that engineering entails a distinctive culture characterised by particular notions of masculinity and instrumental attitudes to study.

Just as class stratum, family background and gender combined to predispose young women for caring occupations, a similar combination - albeit in a different configuration - appears to be at work here. Most of the engineering students' parents are skilled manual workers, located in a craft layer of the working class, and a number of their male relatives have worked in the engineering industry themselves. The lowering of aspirations is an issue in this site, too. Three of the six students 
interviewed had at some point abandoned an established route of academic study, prior to doing this course. The intensity of the course and its assessment demands make it difficult to complete the qualification whilst also being in employment. Students and tutors comment on the adverse effect this can have on students' family lives and relationships, and even on their health.

One student, for example, had had an unhappy experience studying A Levels at sixth form college, where he felt he did not fit in. Having gone to work in telecom engineering, where he enjoyed the practical work, when he began to attend college on day-release as part of his employer's Modern Apprenticeship scheme, he 'struggled with' the course and failed the first year because he 'couldn't be bothered'. Faced with disciplinary procedures at work if he did not re-enroll and successfully complete the course, he had dreaded returning to college. But a new sense of identity went along with an improved experience of learning, including a better relationship with his tutor:

Engineering student 1: First off I was reluctant to change, 'cos I thought, 'Oh my God, back to college again, back to how it was at'. But here I've come in with a clean slate, I've come in with a new attitude, it's worked for me, it's worked for the teachers.

Now more experienced in the workplace, and with a new-found maturity as a father, he felt a sense of belonging, of already having become an engineer:

Engineering student 1: In my eyes and in my boss's eyes, I'm a qualified engineer.

Such previous experiences may have served to heighten students' awareness of the wider educational field and the way in which various qualifications sit within it, including the important 'positional good' that this qualification represents within the industry. Highly instrumental notions of study prevailed among these students, and they generally regarded their college course as an irrelevant but necessary adjunct to their work. Such dissonance between the expected practical content and the actual abstract content of the course, and the resultant disillusionment, have also been noted among engineering students in higher education (see Edward \& Middleton, 2001).

Different opinions about the relevance of the qualification still reflected similar instrumental attitudes towards it. The student described above saw the qualification as a worthwhile credential to gain employment in other sectors if he were ever made redundant by his present employer. The one female student who persisted with the course, in spite of personal difficulties, nevertheless saw the college course as little more than a traditional 'rite of passage' dictated by a sense of 'how things have always been':

Engineering student 2 (female): The company say 'Oh well, just send `em to college, we had to do it, so they can do it... When I was a little girl... When I was a little boy...' you know, that's what it is really.

Another's view altered in the second year, as he found discussions on the job about his college work elicited helpful additional knowledge from workmates: 
Engineering student 3: Yeah, I can relate nearly everything I do in college to something in work, because I speak to people that I work with, they always ask me, 'Oh, what did you do in college yesterday?' and they tell me back things that they know.

In general, however, students ascribed higher value to their learning on the job, working 'on the kit' with 'holes and poles' in the 'real world'.

Whilst the qualification has high currency in the industry, and is seen as crucial for career progression in the particular field of skilled engineering, one of the most important aspects of this site is that vocational identities had already become established among these engineers through their immersion in the workplace, prior to entering the college course. This is, of course, a key contrast with the childcare and healthcare sites. The female student here provides an interesting example. She went through a gradual process of finding opportunities to get away from her 'mundane desk job' in administration, which she believed offered her no hope of career progression, and to 'pick things up' by watching her company's engineers and offering to help them out. Eventually her boss agreed to let her work half-days with them, and she became an engineer. Nevertheless, although it may not initiate the process of becoming, this learning site strongly coheres with and reinforces the vocational culture of engineering, and certainly does not challenge it in any way. Having sketched some of the key interactions between student habitus and learning processes in these sites, we return to our initial questions: How do the cultures of these learning sites transform those who enter them? How can we understand the process of learning, if learning also involves becoming? And how does such becoming happen in VET?

\section{Learning as becoming: the role of vocational habitus}

As we noted earlier, Bourdieu's concept of habitus includes individual aspects of identity as well as collective predispositions or habits structured by factors such as social class and gender. At the same time, habitus must be understood in the context of the 'fields' within which individuals act. For the learning sites we are considering here, the immediate field is constituted by a particular occupation and the VET associated with it, and the recognised development of particular dispositions is of paramount importance in establishing a legitimate position within the field.

Our data confirm that an important aspect of such fields is the vocational culture which pervades them (Bates, 1994a). Vocational cultures, and the notions (Frykholm and Nitzler, 1993) they convey, are underpinned by a 'guiding ideology of practice' (James, 1989) which shapes students' attitudes and serves to unify norms, values and meanings in particular learning sites (see also Bernstein, 1971). In caring occupations, for example, the prevailing ideology is one of 'sacrificial femininity' (Bates, 1991; see also Colley, 2001) linked to affect (the construction, management and display of feelings) and moral rectitude (appearing 'nice', being 'nice', and 'doing good'). In the field of childcare, internationally-used measures of quality are based on assessing the personal attributes of the nursery nurse herself, according to criteria of gentleness, sensitivity, enthusiasm and effort (Scarr, 1998; Tietze et al, 1996). A similar ideology applies in nursing, where caring for patients is also supposed to include caring about them, through warmth, empathy, cheerfulness and involved personal attention (James, 1989, Smith, 1992).

The vocational culture of engineering reflects the other side of the malefemale, rational-emotional hierarchy that prevails in patriarchal capitalist society. It 
privileges logical thinking, technological invention, and judgement divorced from the 'human side' of problems (Kampmeier, 2003; Maull, 1998; McCaulley, 1976). It also encourages an instrumental approach to studying, and fosters the overt expression of physical signifiers of masculinity which, as we have seen, permeate the relevant physical environment.

Our data therefore suggest that a further important factor is related to the vocational culture and the process of learning. In each of the VET sites we have described, a central aspect of students' learning appears to be a process of orientation to a particular identity, a sense of what makes 'the right person for the job'. We term this 'vocational habitus'. Vocational habitus proposes that the learner aspires to a certain combination of dispositions demanded by the vocational culture. It operates in disciplinary ways to dictate how one should properly feel, look, and act, as well as the values, attitudes and beliefs that one should espouse. As such, it is affective and embodied, and calls upon the innermost aspects of learners' own habitus.

Following Hodkinson et al's (1996) theorising of school-to-work transitions, we suggest that structure and agency combine to render the process of acculturation far more complex than a passive absorption into a community of practice. Agency plays its part, since vocational habitus - and the wider vocational culture - is relational and dynamic, co-constructed partly by the dispositions of the students themselves as they construct their own identities. The vocational habitus must be a 'choosable' identity for the individual, one that falls within their 'horizons for action'. Students must have social and family backgrounds, individual preferences and life experiences which pre-dispose them to orient to the vocational habitus and become 'right for the job'. In the three sites we have considered, both gender and specific locations within the working class appear to be important in this regard (as they were for Bates' 'care girls'). However, although such pre-disposition is necessary, it is not sufficient, and much identity-work still remains to be done. In all three sites, our evidence confirms Bates' (1994a) suggestion that this includes the ability to accept the disappointments (especially academic 'failure' and lowered career aspirations), difficulties and privations of entering the field, and to reconstruct them more positively over time.

We therefore describe this identity-work, this transformation of habitus, as a process of orientation to, rather than adoption of, the vocational habitus. We do so, because our evidence suggests that vocational habitus is not unitary or essentialising. It is neither the expression of personality-environment fit suggested by Holland (1997), nor the pre-determined role adjustment suggested by early socialisation theories. Rather, it contains important contradictory tensions which the learner must negotiate. Learners are presented on the one hand with an idealised image of 'the right person for the job' to which they should aspire. In caring occupations, as we have already seen, this identity evokes emotional dedication, while detachment or harshness are presented as anathema. Yet this idealised habitus of 'loving care' is unrealisable. In practice, detachment and even a certain element of harshness form part of a realised habitus that allows learners to perform and cope with emotional labour, to manage their own and others' feelings (Bates, 1991; Hochschild, 1983). Students must orient themselves to both the idealised and the realised ways of being, for the one mitigates the other. Without aspiring to the idealised habitus, the realised habitus might become too harsh, and the student may become 'unsuitable'. Without the tempering effects of the realised habitus, students might be overwhelmed by the emotional demands of the work. 
On the surface, there appear to be fewer such tensions in the vocational habitus of electronic engineering than in the care courses, less disjuncture between idealised and realised identities. The vocational habitus promotes rational instrumentality as its ideal, but this also appears to be realised in students' practice within the learning site and field. The first engineering student we quoted rather exemplifies a sense of tensions resolved as he distances himself from the academic world of sixth form college and finds himself more comfortable in the engineering workplace with its 'holes and poles'. His becoming is reinforced by an easy sense of belonging, perceived by himself and his employer as a 'qualified engineer' already. Perhaps the most evident tension in this site is between the idealised identity of 'student' constructed by FE funding régimes - retained on their course, intrinsically motivated, attending regularly, and 'achieving' - and the realised identity of 'engineer' - able to persist and endure the course despite its perceived irrelevance and the often painful personal difficulties it presents. In this respect, the idealised vocational habitus is rational, detached, logical: but the realised habitus demands the emotional comfort of belonging, as well as disciplinary work to suppress painful feelings. Just because engineers' emotions are less visible, this does not mean they are absent. The invisibility of emotion in the culture of the engineering site may be explained by Bourdieu's observation that, '...both in social perception and in language, the masculine gender appears as non-marked, in a sense neuter, in opposition to the feminine, which is explicitly characterized' (2001, p.9).

We are mindful here of avoiding a purely deterministic view of vocational becoming: newcomers to a field or learning site do of course bring with them the possibility of engendering change (Lave and Wenger, 1991). However, where social structures impact strongly on the vocational culture and habitus through (for example) gender-stereotyping, change is difficult. Tutors are likely to be immersed in the vocational culture themselves, since most have usually been employed in the associated occupation before they became teachers in FE. It may be hard for them to perceive - let alone implement - opportunities for change. Where tutors have sought to transform the learning culture, this has sometimes depended on changing themselves rather than altering technical aspects of pedagogy or curriculum within the learning site (see Colley, 2002b). On an institutional level, colleges may present photographs of women doing engineering or male nursery nurses in their prospectus, as a way of trying to alter the community of practice by attracting newcomers with different 'characteristic biographies', but far more than this would seem necessary to challenge such established masculine or feminine vocational cultures. Cultural processes of VET, including individual choices and preferences, are more likely to be those of mutual reinforcement and cultural reproduction.

As Hodkinson and Bloomer (2000) have shown in the context of a sixth form college, the price of strongly inclusive learning cultures is very often the exclusion of those who do not 'fit'. Our data suggest that this is likely to be the result where an individual rejects or resists the vocational habitus. We have seen how that exclusionary process operated in the CACHE site for students who would or could not orient to the required vocational habitus. This resonates with Bates' argument that VET often serves to mediate 'between family background, education and the labour market through processes of screening young people for what were essentially social attributes' (1991, p.233), and subsequently acts as a disciplinary process to 'filter out' those who are unable to adapt to the demands of the vocational culture. This process may also be seen, however, to reflect agency on the part of the learner, resisting 
'choices' imposed on them, and moving on to other options within their horizons for action.

The healthcare course appears to be less exclusionary, arguably because there is relatively low synergy between the college course and work placements, and this lessens both the potential and the demand for developing the requisite vocational habitus. Yet by the same token, the site also appears to be less including in terms of students' entry into the field of professional nursing and associated healthcare work, as suggested by students' tentative or lowered aspirations by the end of their course. (An example of a vocational learning site which offers little exposure to the vocational habitus can be seen in and Wahlberg and Gleeson's account (2004) of a Business Studies course, also within the TLC project. The tenuous nature of students' commitment to the official goals for the course appears to confirm our analysis here.) By contrast, in the engineering site, the workplace has already largely done the filtering work before students enter their college course, yet we can still see the way in which the learning site reinforces the vocational habitus. Moreover, disciplinary processes of VET are evident here too: the demands of completing the course are intense, the more so because of its perceived irrelevance. Full entry into the community of practice of engineers is still mediated and regulated by VET through its requirement for instrumental persistence and self-sacrifice in respect of family and social life.

It appears, then, that VET may fulfil its role of 'filtering' and disciplinary socialisation (Bates, 1991) to different degrees, depending on the extent to which it immerses students in the vocational culture and demands their orientation to the vocational habitus. In the three examples we have discussed, the healthcare site appears the least immersing in this sense. The childcare course is strongly immersing, evidenced by the growing - and eventually complete - sense of becoming a nursery nurse for successful students. The engineering course is so embedded in the vocational culture that its role is one of deepening the immersion of the workplace, and accordingly, learners often perceive themselves as engineers rather than as 'engineering students'.

The evidence from our learning sites suggests that the possibility of becoming depends upon both the conditions of the vocational field beyond the college and the learning site, and upon the habitus of the students. Close synergy between the college course and the work placement may allow more effective learning. But we have to note here that such learning may also involve the effective reproduction of social inequalities: for example, the ascription of working class girls to low-paid, low-status jobs such as personal care; the preservation of higher-paid, craft-status, technical work largely for working class men; and for both genders - although expressed in very different ways - the stressful demands of working upon one's own feelings in negotiating vocational habitus. Learning in VET should therefore be analysed in terms of classed and gendered relations of power within the vocational field, the educational field and society at large.

\section{Vocational habitus conveys both sense and sensibility}

So what might our concept of 'vocational habitus' contribute to previous explanations of socialisation - and to our understanding of learning cultures in FE? We have been attempting to develop an understanding of this complex aspect of the cultural processes at work in three of our learning sites. One of the wider implications of the discussion is to question the dominant view that, in the era of late modernity, when there appears to be unprecedented choice and the decline of many traditional 
forces and institutions, identity-work amounts largely to a 'reflexive project of the self' (see for example Giddens, 1991). Vocational habitus allows us a concept to help describe the fact that VET does encourage a 'reflexive project of the self', but that this project is often tightly bounded, both in relation to one's existing habitus, and in accordance with a disciplinary discourse about the self that one has to become. The process of learning as becoming is one that is actively co-constructed by students, but the possibilities are not boundless for most young people in VET.

On the basis of our analysis and interpretation of vocational becoming in our three exemplar sites, we would argue that the concept of vocational habitus promises two developments. First, it expresses the original sense of the term 'vocation' as a 'calling', and therefore helps to convey the 'pull' of a vocational culture to include (and therefore also to exclude) people from certain social groupings. It expresses 'the necessary' in the 'choice of the necessary'. It appears to offer a tool for thinking about the way in which practices are regulated within that culture, in ways that produce new identities but also reproduce existing ones, such as gender stereotypes. It therefore expresses 'sense', as a sense of one's 'proper place', and conveys what Bourdieu describes as 'un sens pratique', 'practical common sense'. Such 'sense' is an apparently natural - but always socially constructed - sense of the 'right way' to be and to behave in the workplace (Bourdieu, 1977).

Second, it may help us understand the importance of emotional aspects of learning revealed by our data. The Concise Oxford Dictionary states that a vocation is employment that 'requires dedication', and Heller (1979) argues that feelings and morals also have to be learned, along with thoughts and actions. Vocational habitus offers a way of expressing how these learning sites shape students' ability to respond to complex emotional influences and demands within the vocational culture. It can therefore convey not only 'sense' but also 'sensibility'. In doing so, it renders visible aspects of the hidden curriculum of these learning sites, and in particular the role of class and gender in socially reproductive processes. This brings us back to the starting point of this paper: the relationship between the process of learning and the construction of identity. As has been suggested by Roseneil and Seymour (1999, p. 2):

All identities are not equally available to all of us, and all identities are not equally culturally valued. Identities are fundamentally enmeshed in relations of power.

\section{Conclusions}

If we are to 'think more about the process of learning' in VET as Jessup (1991) urged, we need to think about learning more broadly than official accounts suggest. We need to consider its social, cultural and emotional aspects, its unwritten and hidden curricula, and go beyond explanations related to prescribed curricula and the acquisition of technical skills and knowledge. VET may be different from learning solely in the workplace, but it is deeply influenced by patterns of employment and social role allocation that are established outside the college.

In these VET sites at least, our data supports the view that learning entails a process of becoming. Students find themselves included as they orient themselves to a vocational habitus - a set of dispositions derived from both idealised and realised identities, and informed by the notions and guiding ideologies of the vocational culture. The concept of vocational habitus allows us to think about 'sense' - the sense of one's proper place. It expresses the structural pull that certain occupations have for 
young people from 'characteristic biographies/trajectories' (Lave \& Wenger, 1991, p.55), and the agentic ways in which vocational cultures are co-constructed by students, tutors and dominant discourses within VET. Vocational habitus can also remind us of 'sensibility', in helping us to think about emotional aspects of learning, and the deep engagement that VET demands of young people as they move into particular sectors of the labour market.

All of this suggests that learning cultures do indeed work to transform those who enter them, but that attempts to transform learning cultures in VET may themselves be difficult to effect. Such transformations implicate the complex and mutually constituting relationships between the field of a vocational culture and the formation of the vocational habitus. In this setting, initiatives which reflect dominant concepts of learning, and which fail to account for learning as becoming, appear least likely to impact beneficially on learning cultures.

\section{Acknowledgments}

1. Transforming Learning Cultures in Further Education is funded by the Economic and Social Research Council within Phase II of its Teaching and Learning Research Programme (Award No. L139251025).

2. We are grateful to the rest of the TLC project team for their contributions to the development of this paper.

3. We are also grateful to the anonymous referees of this journal for their comments.

Project Website: http://www.ex.ac.uk/sell/tlc

\section{Project contact:}

Hilary Olek, Project Administrator, University of Exeter, School of Education and Lifelong Learning, Heavitree Road, Exeter EX1 2LU. Tel 01392-264865 e-mail: H.E.Olek@ex.ac.uk

\section{References}

Armitage, A., Byant, R., Dunnill, R., Hayes, D., Hudson, A., Kent, J., Lawes, S. \& Renwick, M. (2003) Teaching and Training in Post-Compulsory Education, $2^{\text {nd }}$ edn. Maidenhead: Open University Press.

Bates, I. (1984) From vocational guidance to life skills: historical perspectives on careers education, in I. Bates, J. Clarke, P. Cohen, D. Finn, R. Moore, \& P. Willis (Eds) Schooling for the Dole? The New Vocationalism. London: Macmillan.

Bates, I. (1991) Closely observed training: an exploration of links between social structures, training \& identity, International Studies in Sociology of Education 1, pp. 225-243.

Bates, I. (1994a) A job which is 'right for me'? Social class, gender and individualization, in I. Bates, \& G. Riseborough (Eds) Youth and Inequality. Buckingham: Open University Press.

Bates, I. (1994b) 'When I have my own studio...': the making and shaping of 'designer' careers, in I.Bates, \& G.Riseborough (Eds) Youth and Inequality. Buckingham: Open University Press.

Bernstein, B. (1971) On the classification and framing of educational knowledge, in M.D.F. Young (Ed) Knowledge and Control: New Directions for the Sociology of Education. London: Collier-Macmillan. 
Bourdieu, P. (1977) Outline of A Theory of Practice. Cambridge: Cambridge University Press.

Bourdieu, P. (1982) Leçon sur la leçon. Paris: Les Editions de Minuit.

Bourdieu, P. (1986) Distinction: A Social Critique of the Judgement of Taste. London: Routledge.

Bourdieu, P. (2001) Masculine Domination (trans. R.Nice). Cambridge: Polity.

Castling, A. (1996) Competence-based Teaching and Training. London: City \& Guilds Macmillan.

Coffey, A. \& Atkinson, P. (1994) Occupational Socialization and Working Lives. Cardiff Papers in Qualitative Research. Aldershot: Avebury.

Colley, H. (2001) Righting re-writings of the myth of Mentor: a critical perspective on career guidance mentoring, British Journal of Guidance and Counselling, 29 (2), pp. 177-198.

Colley, H. (2002a) CACHE Diploma case study 2. Unpublished TLC Project Working Paper.

Colley, H. (2002b) From childcare practitioner to FE tutor: biography, vocational culture and gender in the transition of professional identities, paper presented at the British Educational Research Association Annual Conference, University of Exeter, 12-14 September 2002.

Colley, H. (2003a) 'Children can wind you up!': learning to labour in the nursery, paper presented at the Gender and Education Association Conference:

Revisiting Feminist Perspectives on Gender and Education, University of Sheffield, 14-16 April 2003.

Colley, H. (2003b) Learning to do emotional labour: class, gender and the reform of habitus in the training of nursery nurses, paper presented at the conference Experiential, Community and Workbased: Researching Learning outside the Academy, Centre for Research in Lifelong Learning, Glasgow Caledonian University, 27-29 June 2003.

Colley, H., Hodkinson, P. \& Malcolm, J. (2003) Informality and Formality in Learning. London: Learning \& Skills Research Centre.

Curzon, L.B. (Ed) (1990) Teaching in Further Education, $4^{\text {th }}$ edn. London: Cassell.

Davies, J. \& Tedder, M. (2004) [title of paper in same JVET issue]

Department for Education \& Skills (2001) Participation in education, training and employment by 16-18 year olds in England: 1999 \& 2000, Statistical First Release 30/2001. Available at http://www.dfes.gov.uk/rsgateway/DB/SFR/s000273/sfr30-2001.pdf, accessed on 10 December 2003.

Edward, N.S. \& Middleton, J.C.R. (2001) Occupational socialisation - a new model of the engineer's formation, paper presented at the International Conference on Engineering Education at Oslo, 6-10 August 2001.

Frykholm, C.-U. \& Nitzler, R. (1993) Working life as a pedagogical discourse: empirical studies of vocational and career education based on theories of Bourdieu and Bernstein, Journal of Curriculum Studies, 25 (5), pp. 433-444.

FENTO (2003) Standards for teaching and supporting learning in further education in England and Wales. Available at http://www.fento.org/staff_dev/teach_stan.pdf, accessed on 10 December 2003.

Giddens, A. (1991) Modernity and Self-Identity: Self and Society in the Late Modern Age. Cambridge: Polity Press

Wahlberg, M. \& Gleeson, D. (2004) [title of paper in same JVET issue]

Heller, A. (1979) A Theory of Feelings. Assen: Van Gorcum. 
Herriot, P. \& Pemberton, C. (1996) Contracting careers, Human Relations, 49, pp. 757-790.

Hochschild, A.R. (1983) The Managed Heart: Commercialization of Human Feeling. Berkeley \& Los Angeles: University of California Press.

Hodkinson, P., Sparkes, A.C., \& Hodkinson, H. (1996) Triumphs and Tears: Young People, Markets and the Transition from School to Work. London: David Fulton.

Hodkinson, P. \& Bloomer, M. (2000) Stokingham Sixth Form College: institutional culture and dispositions to learning, British Journal of Sociology of Education, 21 (2), pp. 187-202.

Hodkinson, P. \& James, D. (2004) [title of paper in same JVET issue]

Holland, J.L. (1959) A Theory of Vocational Choice, Journal of Counseling Psychology, 6, pp. 35-45.

Holland, J.L. (1997) Making Vocational Choices: A theory of vocational personalities and work environments, $3^{\text {rd }}$ edn. Odessa: Psychological Assessment Resources.

Honey, P. \& Mumford, A. (1992) The Manual of Learning Styles. Maidenhead: Peter Honey.

James, D. \& Diment, K. (2002) HNC Engineering case study. Unpublished TLC Project Working Paper.

James, N. (1989) Emotional labour: skill and work in the social regulation of feelings, Sociological Review, 37(1), pp. 15-42.

Jessup, G. (1991) Outcomes: NVQs and the Emerging Model of Education and Training. London: Falmer Press.

Kampmeier, A.S. (Ed) (2003) Gender and Qualification: Final Report. Flensburg: University of Flensburg.

Killeen, J. (1996) Career theory, in A.G. Watts, B. Law, J. Killeen, J.M. Kidd, \& R. Hawthorn, Rethinking Careers Education and Guidance: Theory, Policy and Practice. London: Routledge.

Lave, J. \& Wenger, E. (1991) Situated Learning. Cambridge: Cambridge University Press.

Low Pay Unit (2002) Occupational pay rates: nursery nurses. Available at http://www.lowpayunit.org.uk/research/payrates/nurserynurse.shtml, accessed on 30 July 2003.

Maull, W.M. (1998) An Investigation into the Development of Engineering Students' Conceptual Understandings of Mathematics. Unpublished $\mathrm{PhD}$ thesis, University of Plymouth.

McCaulley, M.H. (1976) Psychological types in engineering: implications for teaching, Engineering Education, 66, pp. 729-736.

Reece, I. \& Walker, S. (1996) A practical guide to Teaching, Training and Learning. Sunderland: Business Education Publishers Limited.

Rikowski, G. (2001) Education for industry: a complex technicism, Journal of Education \& Work, 14(1), pp. 29-49.

Riseborough, G. (1994a) Learning a living or living a learning? An ethnography of BTEC National Diploma students, in I. Bates, \& G. Riseborough (Eds) Youth and Inequality. Buckingham: Open University Press.

Riseborough, G. (1994b) GBH - the Gobbo Barmy Harmy: one day in the life of 'the YTS boys', in I. Bates, \& G. Riseborough (Eds) Youth and Inequality. Buckingham: Open University Press.

Roseneil, S. \& Seymour, J. (1999) Practising Identities: Power and Resistance. Basingstoke: Macmillan Press. 
Scarr, S. (1998) American child care today, American Psychologist, 53, pp. 95-108.

Smith, P. (1992) The Emotional Labour of Nursing: How Nurses Care. Basingstoke: Macmillan.

Tedder, M. (2002) BTEC National Diploma in Health Studies case study 2. Unpublished TLC Project Working Paper.

Tietze, W., Cryer, D., Bairrao, J., Palacios, J. \& Wetzel, G. (1996) Comparisons of observed process quality in early child care and education programmes in five countries, Early Childhood Research Quarterly, 11(4), pp. 447-475.

Wacquant, L.J.D. (1989) Towards a reflexive sociology: a workshop with Pierre Bourdieu, Sociological Theory, 7, pp. 26-63.

Willis, P. (1977) Learning to Labour. Farnborough: Saxon House. 